\title{
Impacts of wind forcing on sea level variations in the East China Sea: Local and remote effects
}

\author{
Yanfang $\mathrm{Li}^{\mathrm{a}, *}$, Juncheng Zuo ${ }^{\mathrm{b}}$, Qing Lu ${ }^{\mathrm{c}}$, Hua Zhang ${ }^{\mathrm{a}}$, Meixiang Chen ${ }^{\mathrm{b}}$ \\ ${ }^{a}$ Key Laboratory of Coastal Environmental Processes and Ecological Remediation, Yantai Institute of Coastal Zone Research, Chinese Academy of Sciences, Chunhui Rd 17, \\ Laishan District, Yantai, China \\ ${ }^{\mathrm{b}}$ Institute of Physical Oceanography, Hohai University, Xikang Rd 1, Gulou District, Nanjing, China \\ c State Key Laboratory of Satellite Ocean Environment Dynamics, Second Institute of Oceanography, State Oceanic Administration, Baochubei Rd 36, Xihu District, Hangzhou, China
}

\section{A R T I C L E I N F O}

\section{Article history:}

Received 13 May 2015

Received in revised form 15 August 2015

Accepted 15 October 2015

Available online 21 October 2015

\section{Keywords:}

East China Sea

Sea level variation

Seasonal

Inter-annual

Remote Pacific wind

\begin{abstract}
A B S T R A C T
The regional sea level variation in the East China Sea (ECS) was influenced not only by local factors but also by remote wind from adjoining ocean with the oceanic connectivity influenced by upper-ocean circulation. The satellite altimeter observations showed that from 1993 to 2008, the inter-annual sea level variation in the ECS was negatively related to the strength of Kuroshio. To investigate the relative role of local and remote wind, two sensitive experiments were carried out using the POP model. Model experiments revealed that windinduced redistributions of water played a significant role in the sea level variation of the ECS. The seasonal variations were induced by both local winds and remote Pacific wind stress with approximately equal contribution. However, on the inter-annual sea level variations, the remote wind forcing over the North Pacific could contribute substantially more than that of local wind which modulated sea level immediately. Remote wind influenced the China Sea in forms of changing of wind stress curl and ocean currents, which influenced the intensity of the Kuroshio, especially during El Nino episodes.
\end{abstract}

c) 2015 Elsevier B.V. All rights reserved.

\section{Contents}

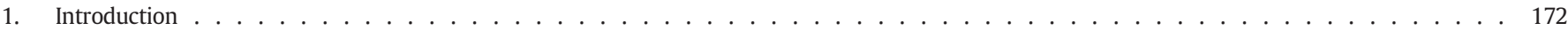

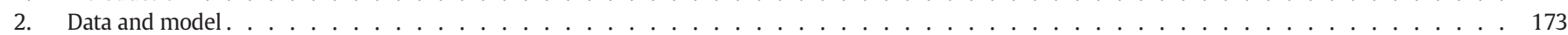

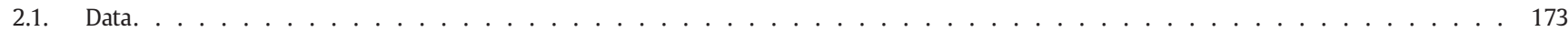

2.1.1. Altimeter data . . . . . . . . . . . . . . . . . . . . . . . . . . . . . . . . . 173

2.1.2. Ocean current data . . . . . . . . . . . . . . . . . . . . . . . . . . . . . . . . . 174

2.1.3. Nino Index . . . . . . . . . . . . . . . . . . . . . . . . . . . . . . . . . . . . . . . . . . . . .

2.2. Model setup . . . . . . . . . . . . . . . . . . . . . . . . . . . . . . . . . . . . . . . . . . . . . . . . . . . . .

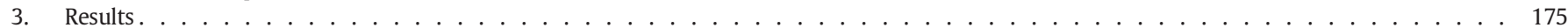

3.1. Model validation . . . . . . . . . . . . . . . . . . . . . . . . . . . . . . 175

3.2. Connection between sea level in the ECS and the Kuroshio . . . . . . . . . . . . . . . . . . . . . . . . . . . . . . . 175

3.3. Response of sea level to El Nino . . . . . . . . . . . . . . . . . . . . . . . . . . . . . . . . . . . . . . . . 176

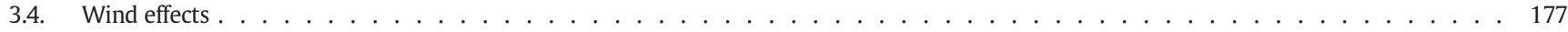

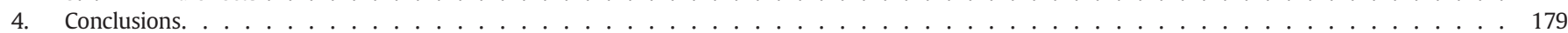

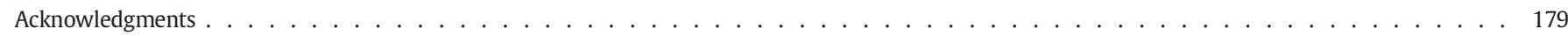

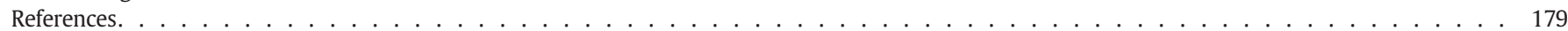

* Corresponding author at: Key Laboratory of Coastal Environmental Processes and Ecological Remediation, Yantai Institute of Coastal Zone Research, Chinese Academy of Sciences, Yantai, China. Tel.: + 86535 2109154; fax: + 865352109000

E-mail address: yfli@yic.ac.cn (Y. Li).

\section{Introduction}

Regional sea level variability can be attributed to ocean circulation, ocean warming, exchange of freshwater, surface wind stress, and other factors (Yamagata et al., 1985; Kohl and Stammer, 2008; Vinogradov et al., 2008; Lombard et al., 2009; Stammer et al., 2013). 
Revealing the causes underlying sea level variability in the East China Sea (ECS, Fig. 1) has been the subject of numerous studies using data analysis and numerical modeling. Located at the mid-latitude, the ECS shows prominent seasonal variability in the sea level, which can be explained by steric change (Yan et al., 2007). Besides the seasonal signals, quasi-biennial cycle and other inter-annual oscillation were also found to be prominent in the ECS's sea level (Yan et al., 2007), and the inter-annual variability was negatively correlated with the Pacific decadal oscillation and ENSO (Yan et al., 2008; Han et al., 2010; Liu et al., 2010; Zuo et al., 2012). On the inter-annual and longer time scales, regional sea level changes are closely tied to the upper-ocean circulation, which reflects the geographical redistribution of upper-ocean water masses (Qiu and Chen, 2012). Wang et al. (2001) pointed out that the spatial patterns of the principal components of the interannual sea level variation in the ECS correlate closely with the change of oceanic currents. The geotropic transport of the Kuroshio causes the dynamic sea level variation in the ECS and the Japanese East Sea (Ichikawa and Chaen, 2000; Teague et al., 2004; Zuo et al., 2012; Stammer et al., 2013), a weaker Kuroshio would increase the inflow of subtropical water to the Japanese East Sea, accounting for higher sea surface height in the Japan Sea (Gordon and Giulivi, 2004).
The ECS is a western marginal sea of the Pacific Ocean, the exchanged water between the ECS and the North Pacific (NP) could affect sea level variation. Long waves caused by wind changes from the Pacific Ocean propagated into the ECS, causing upper-ocean circulations to change. Although thermal expansion, freshwater input from melting glacier and ice sheet dominate in global sea level rise (Church and White 2006), wind-induced redistributions of upper-ocean water play a key role in regional sea level trends (Timmermann et al. 2010; Merrifield and Maltrud, 2011). Thus using numerical model and altimeter data, this study is to investigate the impacts of wind stress changes on regional sea level variation in the ECS, and to evaluate the relative contributions due to local wind and remote wind forcing from the NP.

\section{Data and model}

\subsection{Data}

\subsubsection{Altimeter data}

The altimeter products being used in this study were produced by Ssalto/Duacs and distributed by AVISO, with support from CNES in France (http://www.aviso.altimetry.fr/duacs/). Ssalto/Duacs system processes data from all altimeter missions (Saral, Cryosat-2, Jason-1\&2,

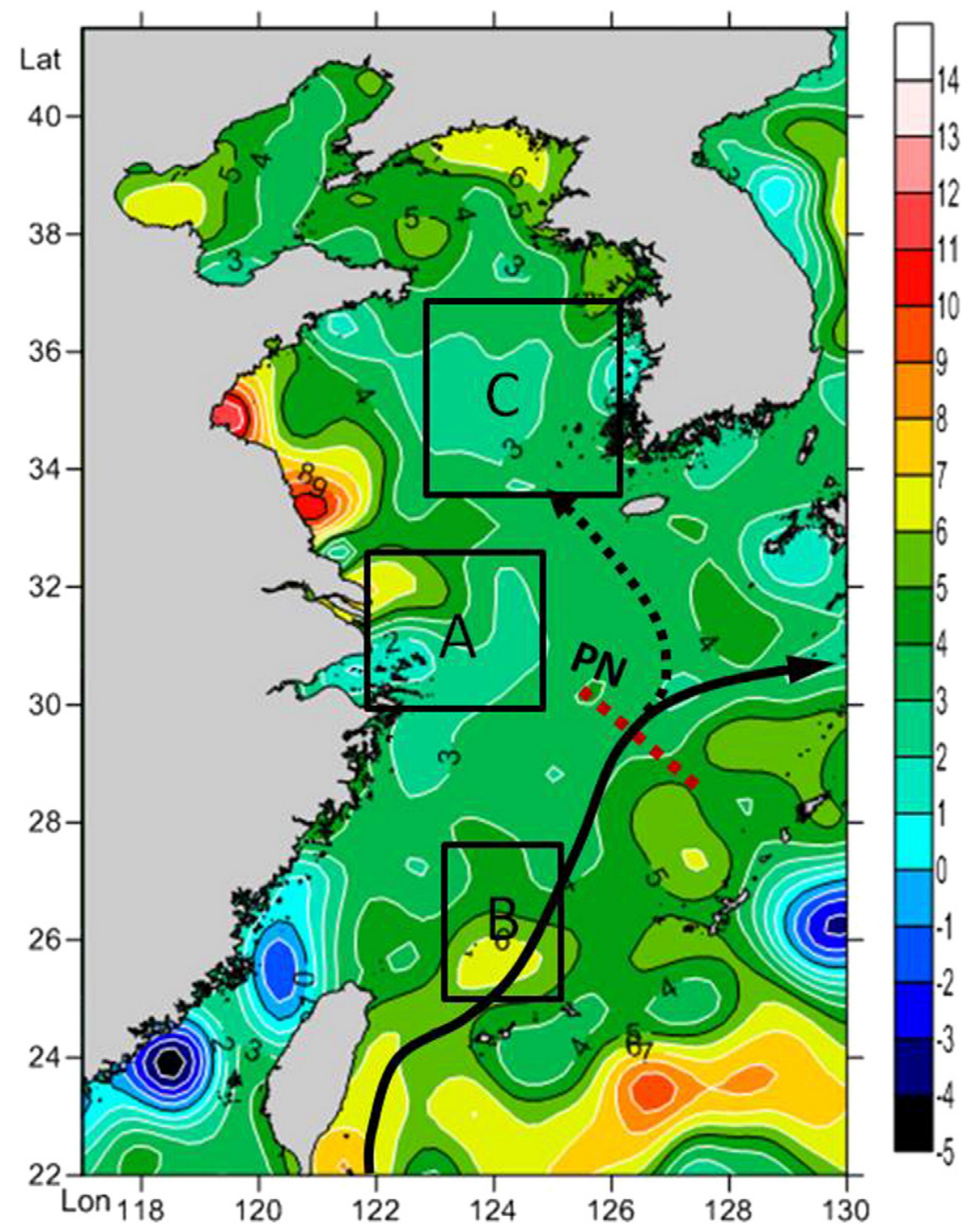

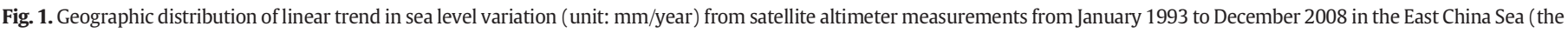

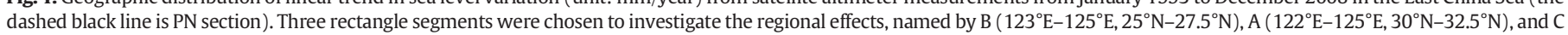
$\left(123^{\circ} \mathrm{E}-126^{\circ} \mathrm{E}, 33.5^{\circ} \mathrm{N}-37^{\circ} \mathrm{N}\right)$ from south to north, respectively. 

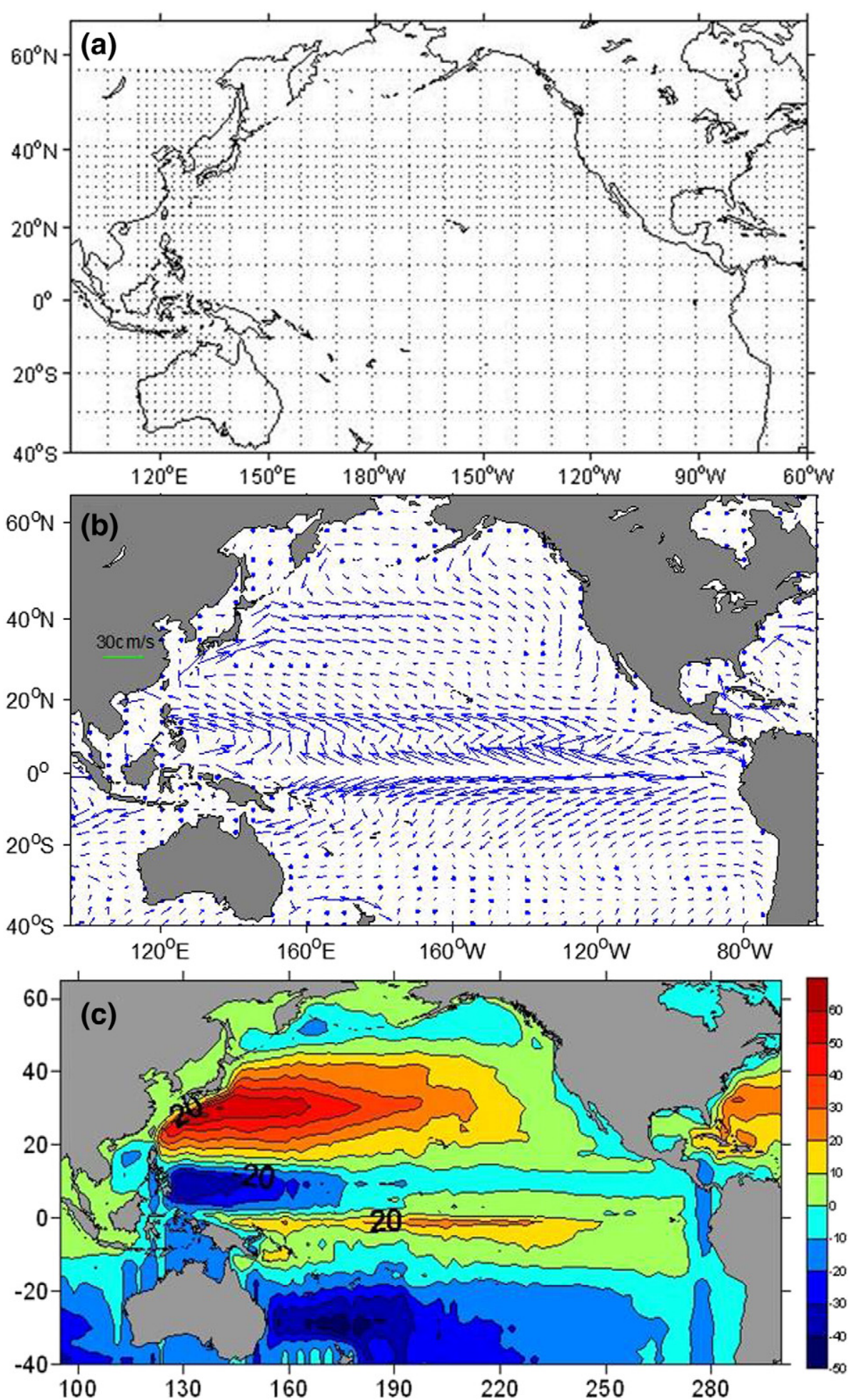

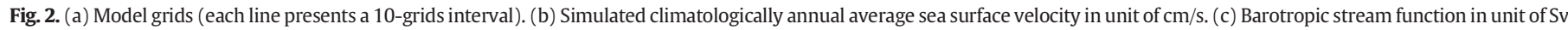
in the North Pacific (positive value presents clockwise gyre, and negative is counter-clockwise, $1 \mathrm{~Sv}=1 \times 10^{6} \mathrm{~m}^{3} / \mathrm{s}$ ).

$T / P$, Envisat, GFO, ERS-1 and ERS-2, and even Geosat) to provide a homogeneous, inter-calibrated, and highly accurate long time series of sea level anomaly (SLA) altimeter data. SLA data cover the period from October 1992 to present with weekly intervals on a one-third degree Mercator grid, while in this study the 17-year data from 1993 to 2008 are used. The various corrections have been applied to the altimeter measurements, including ionosphere delay, dry and wet tropospheric correction, electromagnetic bias, solid Earth and ocean tides, ocean tide loading, pole tide, inverted barometer correction, sea state bias, and instrumental corrections. In this study, this weekly data were first averaged to produce monthly mean data, then applied a three-month moving average.

\subsubsection{Ocean current data}

Ocean current data are provided by the NOAA Climate Prediction Center with $1 / 3$ degree latitude and $1^{\circ}$ longitude grid. The data are 
Table 1

Setup of model simulations in sensitive experiments was as follows.

\begin{tabular}{lllll}
\hline \multirow{2}{*}{ Experiments } & \multicolumn{2}{l}{ Wind (1989-2008) } & \multirow{2}{*}{ Temperature } & Salinity \\
\cline { 2 - 3 } & ECS & NP & & \\
\hline Control & Observed & Observed & Monthly & Monthly \\
Pacific climate & - & climatological & - & - \\
ECS climate & Climatological & - & - & - \\
\hline
\end{tabular}

Note: signal "-" means similar to the control case (indexed with C), case "Pacific climate" means wind stress variation in the NP, case "ECS climate" means wind variation in the ECS "Observed" means realistic monthly wind from 1993 to 2008 with inter-annual varying winds, "climatological" is annual month wind averaged over 1870-1976 without low-frequency signals, and "monthly" means annual average month data provided by Ishii et al. (2009).

real-time ocean analysis and reanalysis from January 1980 to February 2014, and there are 40 geometric vertical levels. The current data were used to calculate the Kuroshio volume transport (KVT) above $700 \mathrm{~m}$ through the PN section (Fig. 1), and to estimate the relationship between Kuroshio and sea level from January 1993 to December 2008.

\subsubsection{Nino Index}

The Nino Index was provided by NOAA, defined as the 3-month means of SST anomalies in the Nino 3.4 region (http://www.cgd.ucar. edu/cas/ENSO/enso.html).

\subsection{Model setup}

The Parallel Ocean Program (POP) is a three-dimensional ocean circulation model on the sphere under hydrostatic and Boussinesq approximations, developed by Los Alamos National Laboratory (Smith et al., 1992 ). The simulated domain was from $40^{\circ} \mathrm{S}$ to $65^{\circ} \mathrm{N}$ and $95^{\circ} \mathrm{E}$ to
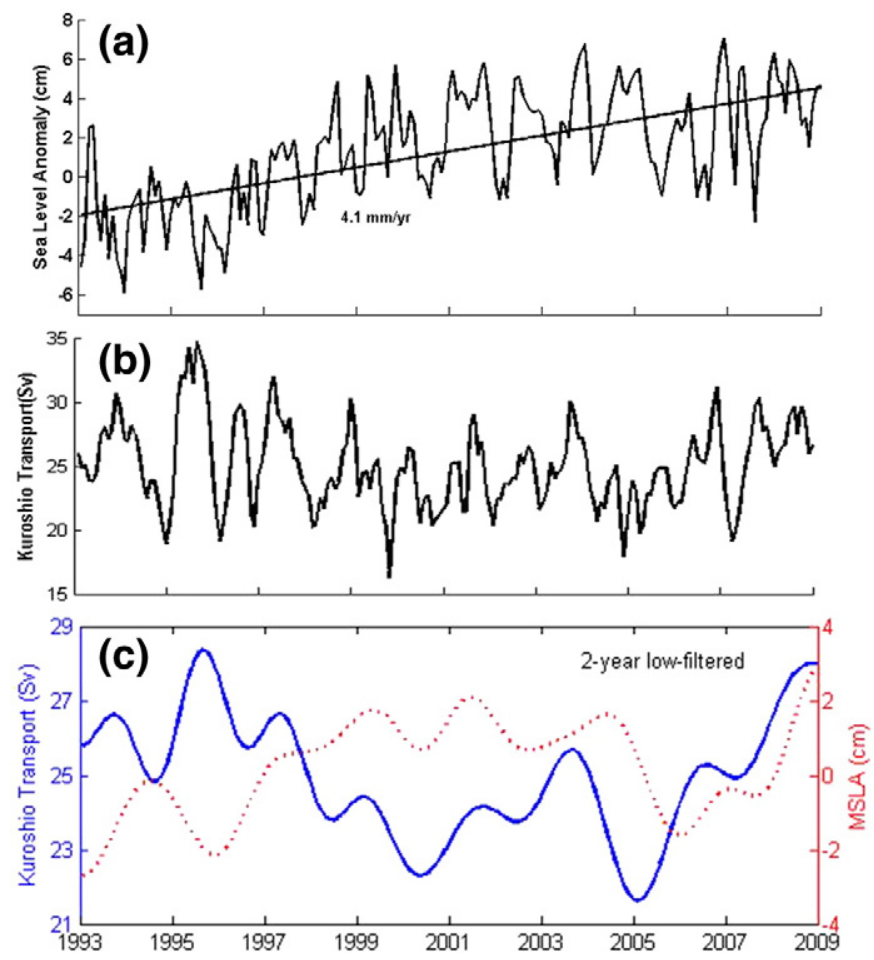

Fig. 3. (a) Time series of monthly mean sea level variation in the ECS from 1993 to 2008 (unit: $\mathrm{cm}$ ). (b) Monthly Kuroshio volume transport (KVT) across the PN section $\left(126^{\circ} \mathrm{E}\right.$ $29^{\circ} \mathrm{N}-128.2^{\circ} \mathrm{E}, 27.5^{\circ} \mathrm{N}$ ) from 1993 to 2008 in unit of Sv. (c) Correlation between low-frequency components of the KVT (blue line) and mean sea level variation (red dashed line) after de-trended and a 2-year low-pass filter. $120^{\circ} \mathrm{W}$ in the North Pacific, with non-uniform horizontal grid. For the $\mathrm{ECS}$, with the range from $22^{\circ} \mathrm{N}$ to $42^{\circ} \mathrm{N}$ and $113^{\circ} \mathrm{E}$ to $135^{\circ} \mathrm{E}$, a grid resolution of $0.25^{\circ} \times 0.25^{\circ}$ was adopted, so as to obtain precise solution to the ECS and improve the calculation efficient , the resolution of other grids in the NP was $1^{\circ}$ (Fig. 2a). The vertical depth was divided into 40 levels, and in the upper ocean (above $500 \mathrm{~m}$ ), there were 19 layers. Open boundary was set in the western and southern boundary with climatological temperature and salinity forcing, the eastern boundary was a closed boundary, and the northern boundary was considered to be a wall because water mass transport through the Bering Strait was negligible.

Initialized with climatological temperature and salinity from the World Ocean Atlas (WOA) 2005, the North Pacific POP was forced with the climatological wind stress of Distributed Active Archive Center for NASA Climate Data System (Hellerman and Rosenstein, 1983) and integrated for several decades to reach a quasi-equilibrium state. After that, the control experiment was carried out for the period of 19892008 , forced by the blended monthly sea wind stress (Zhang et al., 2006) and monthly temperature and salinity data (Ishii et al., 2009).

Two sensitive simulations were designed to explore the relative roles played by the remote Pacific versus local winds on generating sea level variation in the ECS, all the other parameters and forcing were kept unchanged with the exception of wind forcing. The wind forcing consists of different combinations of the observed monthly wind supported by National Climatological Data Center (NCDC) monthly blended data from 1989 to 2000 at $0.25^{\circ}$ resolution and QuikSCAT monthly data from 2000 to 2008 with a 0.5 resolution. All these data were interpolated into the model grid and made a new time series of monthly wind data with uniform resolution (1989-2008). In sensitivity experiment 1 (Pacific climate), we used the inter-annually varying winds in the ECS and climatological monthly winds in the Pacific Ocean. Similarly in the sensitivity experiment 2 (ECS climate) the setup of wind was opposite to that of experiment 1 (Table 1 showed the details of setup). Therefore, the control simulations subtracted those of the Pacific climate case would reveal the variations of the NP influenced by inter-annual wind stress, while the control one subtracted the ECS climate case showed the roles of local wind in the ECS.

\section{Results}

\subsection{Model validation}

To evaluate the model performance, the simulated currents (Fig. 2b) were compared to the previous studies in the NP domain using the model results of the fortieth year. The pattern of annual average sea surface velocity (Fig. 2b) and baratropic currents (Fig. 2c) in the NP was in good agreement with previous simulations (Fujio et al., 1992; Wei et al., 2004; Yang et al., 2010). The sea surface velocity showed a clockwise rotation pattern, the maximum transport of subtropical gyre in the NP at the western boundary can reach up to $60 \mathrm{~Sv}\left(1 \mathrm{~Sv}=10^{6} \mathrm{~m}^{3} / \mathrm{s}\right)$, the subpolar gyre had a maximum about $10 \mathrm{~Sv}$, the North Equatorial Current divided into southern and northern branches nearby $12^{\circ} \mathrm{N}$, the northern branch formed the Kuroshio. There existed a maximum transport value of $30 \mathrm{~Sv}$ in Mindanao cold eddy, the Equatorial Currents is about $20 \mathrm{~Sv}$. The mean sea surface height of simulation in the NP (not shown) distributed similarly to the previous global simulation results of priors (e.g. Masumoto et al., 2004; Wei et al., 2004). The simulated results can well reflect each component of ocean; therefore, further case could be carried out based on the above experiment.

\subsection{Connection between sea level in the ECS and the Kuroshio}

On regional scales, sea level can be affected by changes of oceanic circulations with the redistribution of seawater, which can result in sea level variability on inter-annual to long-term timescales (Lee and 

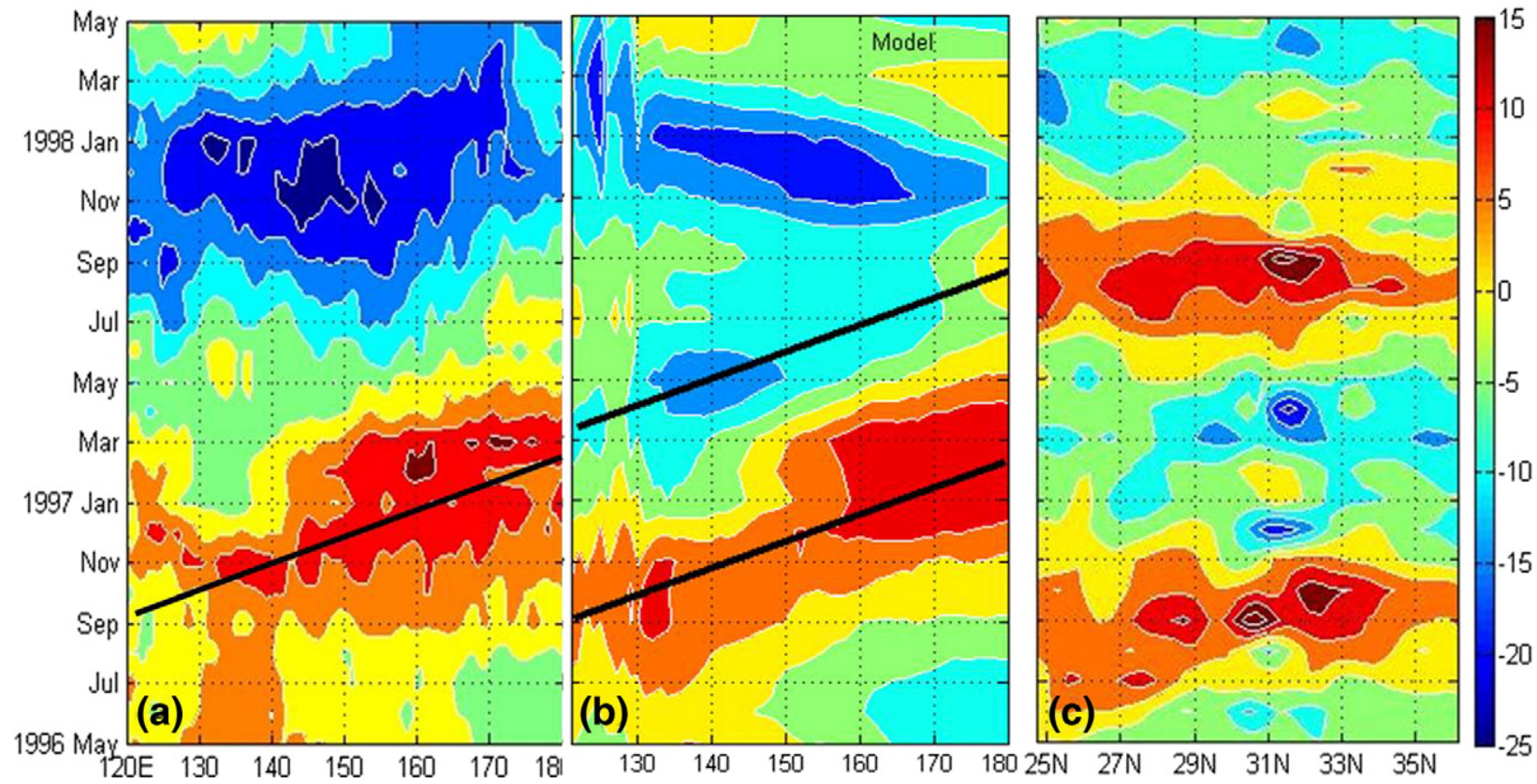

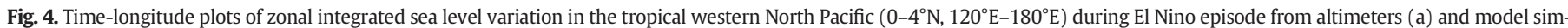

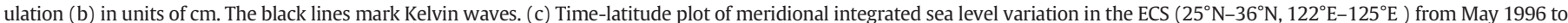
1998.

Takeshi, 2007). The trend of regional mean sea level anomaly in the ECS was calculated with a rising rate of about $4.1 \mathrm{~mm}$ per year from 1993 to 2008 (Fig. 3a), which was significant higher than global trend of $3.3 \pm$ $0.4 \mathrm{~mm}$ per year (Church and White, 2006; Nicholls and Cazenave, 2010). As a significant driving force of hydrodynamic motions in the ECS, the Kuroshio water intrusion events provided great mass of water stirring in the ECS, the Kuroshio has a profound effect on the regional sea level variation surrounding the ECS. Based on monthly current data, the Kuroshio volume transport (KVT) through the PN-line was calculated (Fig. 3b, Wei et al., 2013), the multi-year seasonal average of the KVT through the PN section was about $28 \mathrm{~Sv}\left(1 \mathrm{~Sv}=10^{6} \mathrm{~m}^{3} \mathrm{~s}^{-1}\right)$ from 1993 to 2008. Besides the annual cycle, the KVT exhibited a significant inter-annual variation. Correlation analysis showed that the correlation coefficient was small between the KVT and sea level variation of the ECS on seasonal scale. However, with a two-year low-pass filter, the inter-
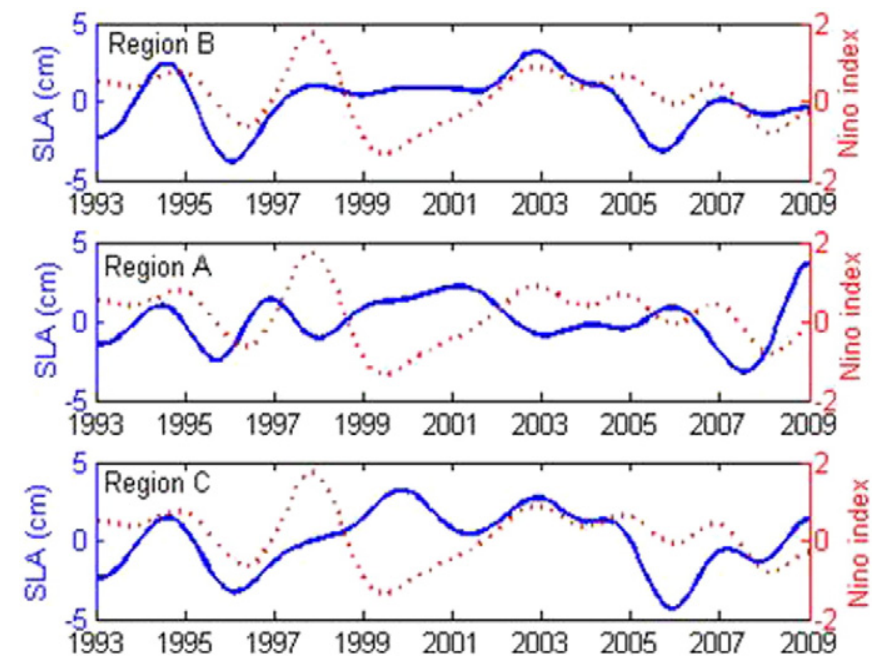

Fig. 5. Correlations between low-frequency sea level variation of three chosen segments and El Nino. The blue solid lines are inter-annual signal of sea level (unit: $\mathrm{cm}$ ), and the red dashed line is El Nino index. annual variation of sea level in the ECS had a good relationship with the KVT, and the maximum significant correlation coefficient was -0.67 ( $p$-value $<0.05$, Fig. $3 c$ ), which revealed that the Kuroshio transport could affect inter-annual changes of sea level in the ECS.

\subsection{Response of sea level to El Nino}

Inter-annual changes in the Pacific basin-wide winds related to ENSO events could change geostrophic boundary transport and result in sea level variations at annual and longer periods (Ryan and Noble, 2006). Fig. 4 showed the sea level variation during the strong El Nino from 1997 to 1998 in the tropical western Pacific. During El Nino the pattern of simulated sea level anomaly (Fig. 4b) was similar to that of altimeter (4a), especially at the onset of El Nino, trade winds anomaly drove Kelvin wave to propagate eastward, causing positive sea level signal to eastern boundary. The discrepancy between simulation and altimeter data mainly resulted from the use of climatically monthly forcing data (temperature and salinity), not real-time ones, and the difference also indirectly revealed the significant role of temperature and salinity on the occurrences and development of El Nino events. Simulation results showed that influenced by the weakened westerly winds, the intensity of the Northern Equatorial Current and Northern Equatorial Counter Current dropped obviously in the west boundary, which agreed with the findings of Wyrtki (1975). From May 1997 to April 1998, volume transport by subtropical gyre of the NP in the western boundary decreased by about $10 \mathrm{~Sv}$ (difference between control run and Pacific climate case), which suggest that during El Nino west boundary current was weakened. The weakened Kuroshio has been observed by Yuan et al. (2001) in 1997 voyage and could influence the ECS.

The fluctuation caused by El Nino in the western boundary of the NP propagated into the China Sea with the Kuroshio. Long waves entered into the East China Sea from right side of Taiwan and propagated northward, the signal showed obvious seasonal feature (Fig. 4c). It was not clear to see the effect caused by El Nino because the strong seasonal signals overshadowed the inter-annual variation. Studies showed that sea level variation in the ECS was connected to El Nino (Han and Huang, 2008; Liu et al., 2009, 2010; Zuo et al., 2012; Wang et al., 2014) with spatial characteristic. Three segments (see 

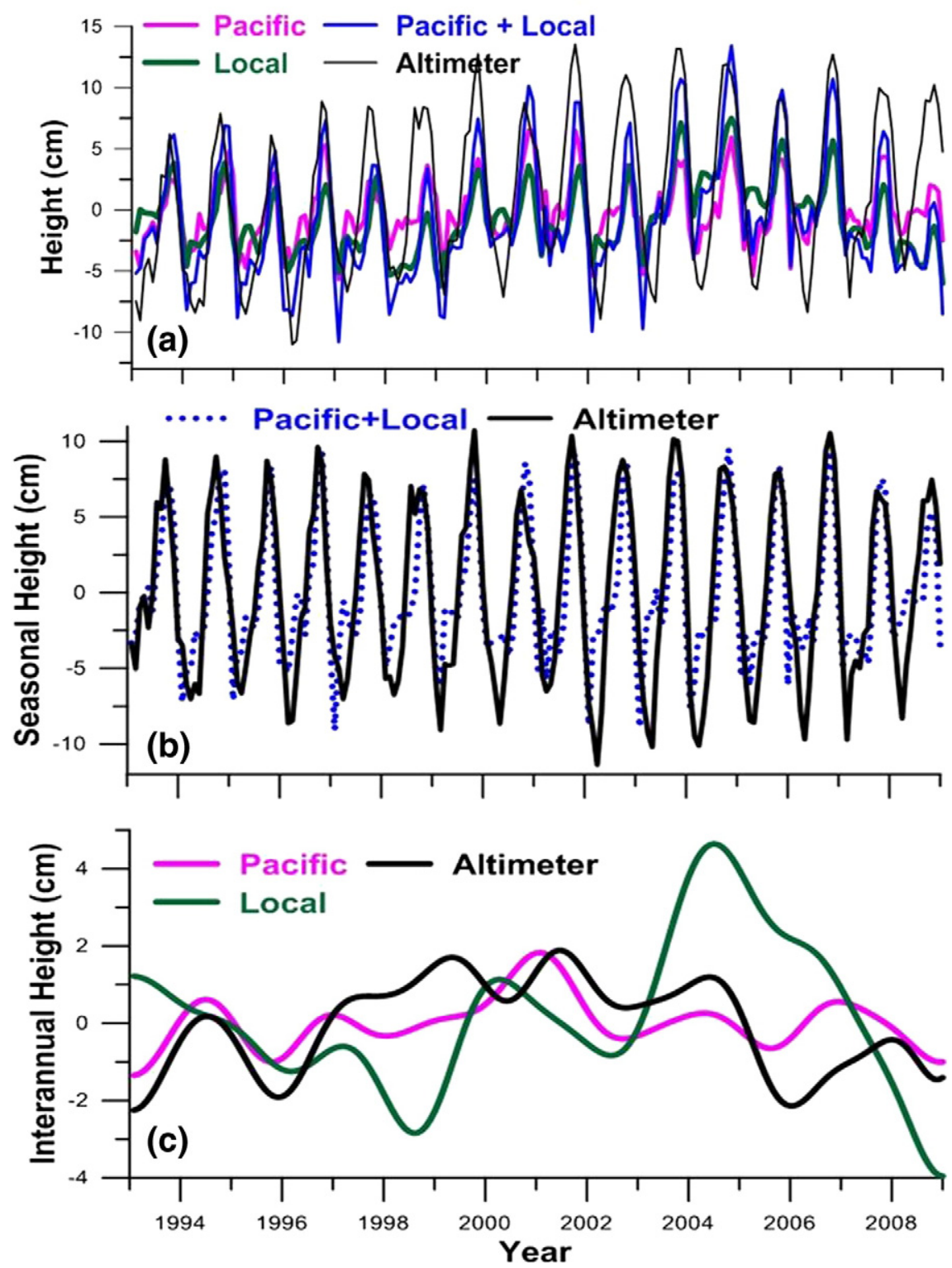

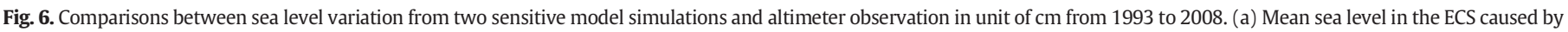

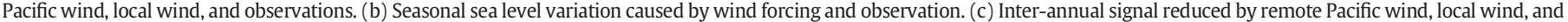

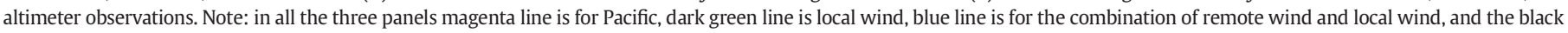
line is the Altimeter data.

Fig. 1, rectangle indexed with prefix "B," "A," and "C" from south to north, respectively) were chosen to study the relationship between sea level and the Kuroshio. The correlation analysis results showed that the links between sea level variation in three regions in the ECS and Nino index behaved asymmetrically (Fig. 5). After a 2-year low-pass filter, the inter-annual sea level in region B correlated to El Nino, with a max coefficient 0.36 ; but maximum coefficient was -0.35 lagging 7 months in region $\mathrm{A}$, and in region $\mathrm{C}$, the correlation coefficient was -0.25 lagging 10 months after Nino index. The fluctuation caused by El Nino can be propagated into the East China Sea from south to the north and resulted in mean sea level inter-annual variation.

\subsection{Wind effects}

Since wind driving upper-ocean circulation is an important contributor for regional sea level variability and long-term trends (Lee and McPhaden, 2008; Han et al., 2010; Timmermann et al., 2010; Zhang et al., 2012; Zuo et al., 2012; Moon et al., 2013), two sensitive experiments were carried out to investigate the effects of local wind and remote wind from adjoining sea on the sea level variation of ECS (Table 1). It was clear to see that regardless of local wind or remote Pacific wind forcing, the simulated mean sea level in the ECS both showed a strong annual variation compared to that of altimeter data with highest sea level in summer (Fig. 6a and b). The correlation coefficient was 0.76 between the ECS's fluctuation generated by the Pacific wind and sea level of altimeter and 0.52 between sea level variation generated by local wind and altimeter observations, respectively. Both changes of local wind and Pacific wind contributed to the sea level change in the ECS. From 1993 to 2008 in the ECS, there was a rising rate of about 4.1 $\mathrm{mm} /$ year (Fig. 3a), the rising rate resulted from local wind anomaly was $0.4 \mathrm{~mm} / \mathrm{year}$, and $0.8 \mathrm{~mm} /$ year caused by remote Pacific wind anomaly (Fig. 6a), which could explain a small part of sea level change. Besides wind and circulation, steric effects played an important role on sea level variation (Marcos et al., 2012; Zhang et al., 2012, 2014), which did not discussed in this text. 

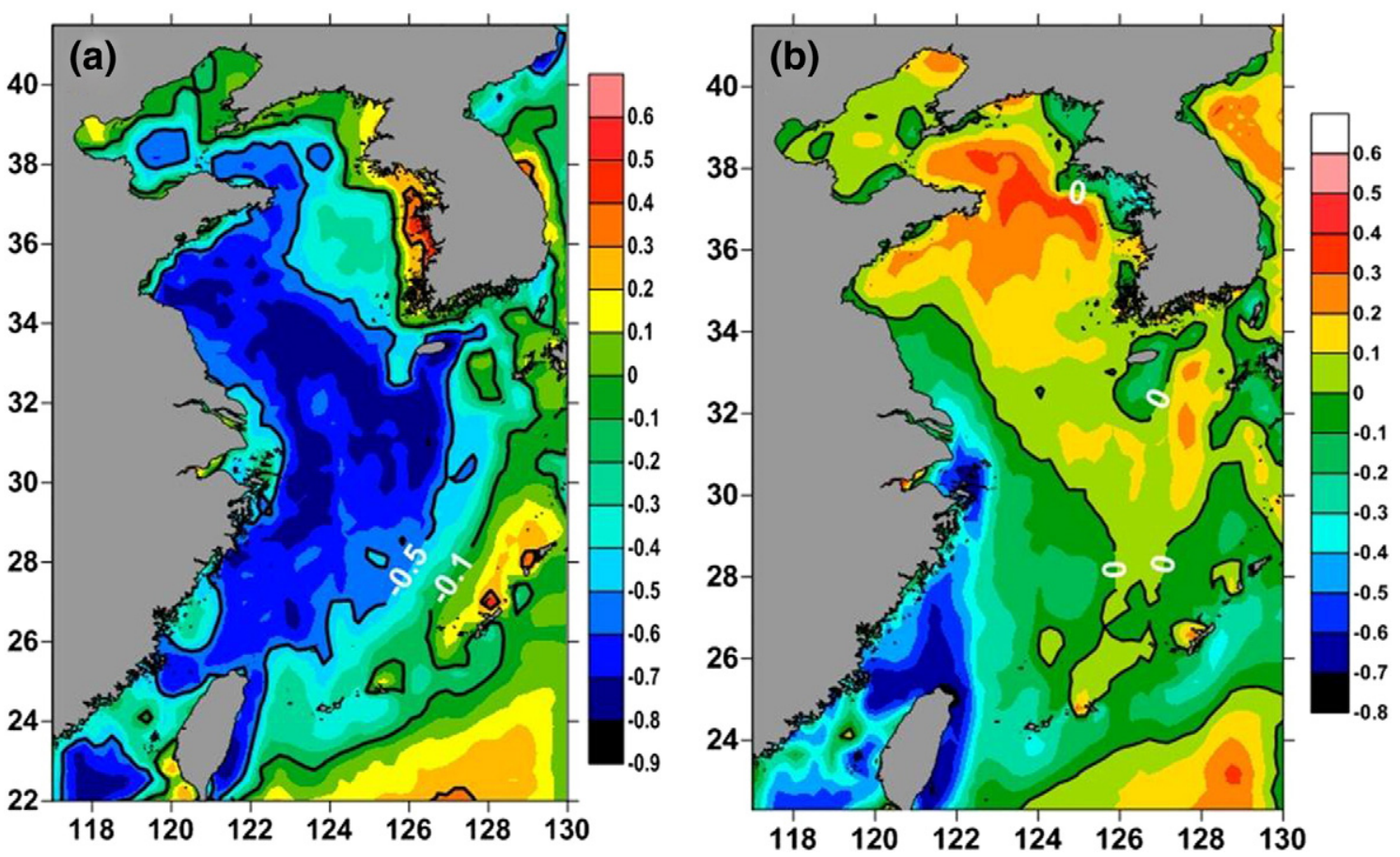

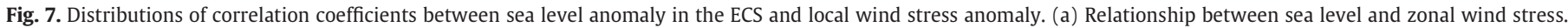
(b) Relationship between sea level and meridional wind stress.

To quantify the contributions of the local wind versus remote Pacific wind, we used the variance $S=1-\left\langle\left(h_{\mathrm{mod}}-h_{\mathrm{obv}}\right)^{2}\right\rangle /\left\langle h_{\mathrm{obv}}^{2}\right\rangle$, where $h_{\mathrm{obv}}$ is the sea level time series in altimeter, $h_{\text {mod }}$ represents the result from two sensitive simulations, and \langle\rangle denotes the summation over time. Extracted the seasonal signal of simulated de-trended sea level variation (Fig. 6b), local wind and remote Pacific wind could explain $40.4 \%$ and $48.8 \%$ of the annual variance of total sea level in the ECS, respectively, indicating that wind played an important role in seasonal sea level variation of ECS, whatever local wind and remote wind. After the seasonal signal being removed, Fig. 6c clearly displayed the low-frequency variations resulted from local wind and Pacific wind. The correlation analysis showed a good relationship between remote Pacific wind and altimeter data with a high coefficient of 0.58 , and the contribution variance can explain $34 \%$ of the inter-annual variance of altimeter observation. The results indicated that the low-frequency sea level variations within the ECS were mainly induced by remote Pacific wind forcing instead of local winds, which was in good agreement with that low-frequency sea level variation around the Philippine was mainly forced by tropical Pacific winds (Zhuang et al., 2013).

Wind stress modulated sea level immediately; it could force seawater to transport toward/off coast, and accumulated/diverged on shore causing high/low sea level, resulting in changes in the convergence/divergence of near-surface Ekman transport. The correlation between wind stress and sea level variation was analyzed. The correlation analysis showed that zonal wind stress worked directly on the sea level. In most regions of the ECS negative correlation between sea level and zonal wind stress reached maximum simultaneously, with significant

Table 2

Sea level change trends of the three chosen segments in the ECS reduced by Altimeter and remote Pacific wind in unit of $\mathrm{mm} / \mathrm{year}$.

\begin{tabular}{llc}
\hline Region & Altimeter & Remote wind \\
\hline B & 3.5 & -1.1 \\
A & 4.8 & 1.2 \\
C & 3.2 & 1.1 \\
\hline
\end{tabular}

correlation coefficient ranging from -0.5 to -0.9 ( $p$-value $<0.05$, Fig. 7), which was in good accordance with the results of Zhang et al. (2012). Remote wind from the Pacific Ocean acted not only on seasonal but also on inter-annual variations of sea level in the ECS. In contrast, local wind mainly modulated the seasonal sea level variations.

Wind in the East China Sea subject to the East-Asia monsoon system has significant seasonal characteristic. Local wind influenced by monsoon system modulated sea level variation in the ECS on annual timescale. On the other hand, wind stress dynamically drives the upper-ocean circulation with seasonal, inter-annual, and long-term variations in the Pacific and leads to changes of subtropical circulation regime. As the bond linking the North Pacific and ECS, the intensity of the Kuroshio could affect the sea level variation in the ECS significantly
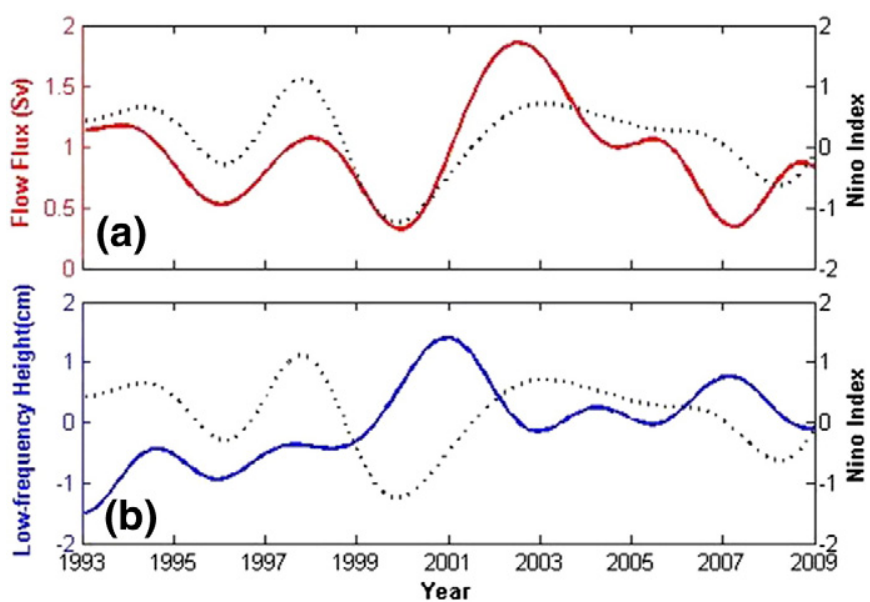

Fig. 8. Low-frequency signal of the Kuroshio flux (Sv) and sea level variation (cm) reduced by remote Pacific wind forcing. (a) Relationship between the Kuroshio flux (red solid line) and El Nino (dashed line). (b) Correlation between modeled sea level variation (blue solid line) and El Nino (dashed line). 
(Zuo et al., 2012) since the Kuroshio carried large amount of energy and heat flux into the China Sea. The response of regional sea level to surface wind variability was evident in the ECS, local wind modulated sea level seasonal fluctuation in the ECS.

The remote wind coming from the Pacific had a complex influence on the ECS's sea level. The remote effect varied spatially on regional sea level variation in the ECS. Table 2 shows the sea level rising trend in the chosen segments (as Fig. 1 displayed), and long-term influence resulting from Pacific climate wind led to a different rising trend in the ECS from south to north. Altimeter data showed that regional sea level change was dramatic north of the Taiwan Island compared to the other two regions, but the rising trend caused by remote Pacific wind was equivalent, which indicated that the fluctuation from Pacific propagated into the ECS northward. In our model experiments, the remote effect coming from Pacific consists of seasonal, inter-annual, and even longer time scale variation. Especially during El Nino episode, the abnormally signal would change the intensity of circulation with the fluctuation propagating into the ECS and result in a response to sea level. The Kuroshio flux anomaly east of Taiwan caused by remote wind displayed high correlations with El Nino (0.61, Fig. 8a), and sea level anomaly generated by inter-annual wind signal was also related to El Nino (correlation coefficient -0.41 , Fig. $8 \mathrm{~b}$ ), as mentioned in Section 3.2, there was relationship between the Kuroshio and sea level variation in the ECS on inter-annual time scale, the model result also revealed the negative correlation. The Ekman transport and long waves propagation was essential to the modulation originated from remote Pacific wind.

\section{Conclusions}

Both local wind and remote wind acted on sea level variation in the East China Sea. To assess the relative role of surface wind associated with the monsoon system and Pacific climate, two sensitive experiments were carried out using POP model from 1993 to 2008. Through comparisons between two sensitive simulations and the control experiment, it is demonstrated that local wind and remote Pacific wind forcing played an equaled role in the seasonal sea level variation of ECS except for dominated steric effects. The altimeter observations revealed that inter-annual sea level variation in the ECS had obvious lowfrequency fluctuation related to El Nino, and the intensity of Kuroshio displayed high correlations with inter-annual sea level of ECS. The simulations confirmed that changes of wind stress would influence sea level variation by Ekman transport and modulations of ocean circulation. Remote Pacific wind stress could explain part of the inter-annual sea level variation and the rest whether caused by steric sea level changes needs a further study.

\section{Acknowledgments}

This work was jointly supported by the Strategic Priority Research Program of the Chinese Academy of Sciences (grant no. XDA11020305), the NSFC project (grant no. 41376028, 41506006, 41576020 and 41276018), the Project of Global Change and Air-Sea interaction under contract (grant no. GASI-03-IPOVAI-04) and the Jiangsu Provincial Natural Science Foundation of China (grant no. BK20140846). The 1/4 gridded blended wind data were provided by NOAA NODC. GODAS data are provided by the NOAA/OAR/ESRL PSD, Boulder, Colorado, USA (http:// www.esrl.noaa.gov/psd/).

\section{References}

Church, J.A., White, N.J., 2006. A 20th century acceleration in global sea-level rise. Geophys. Res. Lett. 33, L01602.

Fujio, S., Kadowaki, T., Imassato, N., 1992. World ocean circulation diagnostically derived from hydrographic and wind stress fields 1 . The velocity field. J. Geophys. Res. 97 (C7), 11163-11176

Gordon, A.L., Giulivi, C.F., 2004. Pacific decadal oscillation and sea level in the Japan/East sea. Deep-Sea Res. I 51 (5), 653-663.
Han, G., Huang, W., 2008. Pacific decadal oscillation and sea level variability in the Bohai, Yellow, and East China Seas. J. Phys. Oceanogr. 38, 2772-2783. http://dx.doi.org/10. 1175/2008JPO3885.1

Han, G., Ohashi, K., Chen, N., Myers, P.G., Nunes, N., Fischer, J., 2010. Decline and partial rebound of the Labrador Current 1993-2004: monitoring ocean currents from altimetric and conductivity-temperature-depth data. J. Geophys. Res. 115, C12012. http://dx.doi.org/10.1029/2009JC006091.

Hellerman, S., Rosenstein, M., 1983. Normal monthly wind stress over the world ocean with error estimates. J. Phys. Oceanogr. 13, 1093-1104.

Ichikawa, H., Chaen, M., 2000. Seasonal variation of heat and freshwater transports by the Kuroshio in the ECS. J. Mar. Syst. 24, 119-129.

Ishii, M., Kimoto, M., Sakamoto, K., 2009. Reevaluation of historical ocean heat content variations with time-varying XBT and MBT depth bias corrections. J. Oceanogr. 65, 287-299.

Kohl, A., Stammer, D., 2008. Decadal sea level changes in the 50-year GECCO ocean synthesis. J. Clim. 21, 1876-1890.

Lee, T., McPhaden, M.J., 2008. Decadal phase change in large-scale sea level and winds in the Indo-Pacific region at the end of the 20th century. Geophys. Res. Lett. 35, L01605. http://dx.doi.org/10.1029/2007GL032419.

Lee, Joon-Soo, Takeshi, Matsuno, 2007. Intrusion of Kuroshio water onto the continental shelf of the East China Sea. J. Oceanogr. 63, 2309-2325.

Liu, X., Liu, Y., Guo, L., Gu, Y., 2009. Change of mean sea level of low-frequency on East China Sea and its relation with ENSO. J. Geod. Geodyn. 29 (4), 55-63.

Liu, X., Liu, Y., Guo, Y., Rong, Z., Gu, Y., Liu, Y., 2010. Interannual changes of sea level in the two regions of East China Sea and different responses to ENSO. Glob. Planet. Chang. $72,215-226$.

Lombard, A., Garric, G., Penduff, T., Molines, J.M., 2009. Regional patterns of observed sea level change: insights from a $1 / 4^{\circ}$ global ocean/sea-ice hindcast. Ocean Dyn. 59 (3), 433-449.

Marcos, M., Tsimplis, M.N., Calafat, F.M., 2012. Inter-annual and decadal sea level variations in the north-western Pacific marginal seas. Prog. Oceanogr. 105, 4-21.

Masumoto, Y., Sasaki, H., Kagimoto, T., Komori, N., Ishida, A., Sasai, Y., Miyama, T., Motoi, T., Mitsudera, H., Takahashi, K., Sakuma, H., Yamagata, T., 2004. A fifty-year eddy-resolving simulation of the world ocean-preliminary outcomes of OFES (OGCM for the Earth Simulator). J. Earth Simulator 1, 35-56.

Merrifield, M.A., Maltrud, M.E., 2011. Regional sea level trends due to a Pacific trade wind intensification. Geophys. Res. Lett. 38, L21605.

Moon, Jae-Hong, Song, Y.T., Bromirski, P.D., Miller, A.J., 2013. Multidecadal regional sea level shifts in the Pacific over 1958-2008. J. Geophys. Res. 118 (12), 7024-7035.

Nicholls, R.J., Cazenave, A., 2010. Sea-level rise and its impact on coastal zones. Sci. Mag. 328 (5985), 1517-1520

Qiu, B., Chen, S., 2012. Multidecadal sea level and gyre circulation variability in the northwestern tropical Pacific Ocean. J. Phys. Oceanogr. 42, 193-206.

Ryan, H.F., Noble, M.A., 2006. Alongshore wind forcing of coastal sea level as a function of frequency. J. Phys. Oceanogr. 36, 2173-2184.

Smith, R.D., Dukowicz, J.K., Malone, R.C., 1992. Parallel ocean general circulation modeling. Physica D 60, 38-61.

Stammer, D., Cazenave, A., Ponte, R.M., Tamisiea, M.E., 2013. Causes for contemporary regional sea level changes. Ann. Rev. Mar. Sci. 5, 21-46.

Teague, W.J., Jacobs, G.A., Mitchell, D.A., Wimbush, M., Watts, D.R., 2004. Decadal current variations in the southwestern Japan/East Sea. J. Oceanogr. 60, 1023-1033.

Timmermann, A., McGregor, S., Jin, F.F., 2010. Wind effects on past and future regional sea level trends in the Southern Indo-Pacific. J. Clim. 23, 4429-4437.

Vinogradov, S.V., Ponte, R.M., Heimbach, P., 2008. The mean seasonal cycle in sea level estimated from a data constrained general circulation model. J. Geophys. Res. 113, $1-15$.

Wang, Y., Xu, H.Z., Zhan, J.G., 2001. Complex principal component analysis of sea level variability over China Seas from TOPEX/Poseidon altimetry. Acta Geodaet. Cartogr. Sin. 30, 173-178 (In Chinese with English abstract).

Wang, L., Wang, J., Yang, J., 2014. The comprehensive analysis of sea level change in the East China Sea. Acta Oceanl. Sin. 36 (1), 28-37 (In Chinese with English abstract).

Wei, Z., Qiao, F., Fang, G., Chio, B., Fang, Y., Wang, X., 2004. Diagnostic study of the world ocean circulation-current field and stream function. Adv. Mar. Sci. 22 (1), 1-15 (in Chinese with English abstract).

Wei, Y., Huang, D., Zhu, X., 2013. Interannual to decadal variability of the Kuroshio Current in the East China Sea from 1955 to 2010 as indicated by in-situ hydrographic data. J. Oceanogr. 69, 571-589. http://dx.doi.org/10.1007/s10872-013-0193-5.

Wyrtki, K., 1975. El Niño-the dynamic response of the equatorial Pacific Ocean to atmospheric forcing. J. Phys. Oceanogr. 5, 572-584.

Yamagata, T., Shibao, Y., Umatani, S., 1985. Interannual variability of the Kuroshio extension and its relation to the Southern Oscillation/El Niño. J. Oceanogr. Soc. Jpn. 41 (4), 274-281. http://dx.doi.org/10.1007/BF02109276.

Yan, M., Zuo, J.C., Du, L., Li, L., Li, P.L., 2007. Sea level variation/change and steric contributions in the East China Sea. Proceedings of the Seventeenth International Offshore and Polar Engineering Conference, Lisbon, Portugal, July 1-6, pp. 2377-2382.

Yan, M., Zuo, J., Fu, S., Chen, M., Cao, Y., 2008. Advances on sea level variation research in global and China Sea. Mar. Environ. Sci. 27 (2), 197-200 (in Chinese with English abstract).

Yang, Y., Zhou, W., Dong, D., 2010. Diagnostic calculation of the oceanic circulation. Mar. Sci. Bull. 12 (1), 30-38.

Yuan, Y.C., Liu, Y.G., Su, J.L., 2001. Variability of the Kuroshio in the East China Sea during El Nino to La Nina a phenomenon of 1997 and 1998. Chin. J. Geophys. 44 (2), 199-210.

Zhang, H.M., Bates, J.J., Reynolds, R.W., 2006. Assessment of composite global sampling: sea surface wind speed. Geophys. Res. Lett. 33, L17714. http://dx.doi.org/10.1029/ 2006GL027086. 
Zhang, S., Du, L., Chang, Y., Li, L., 2012. Interannual and decadal variation of sea level in the East China Sea. Proceedings of the Twenty-Second (2012) International Offshore and Polar Engineering Conference, Rhodes, Greece, June 17-22, pp. 693-700.

Zhang, S., Du, L., Wang, H., Jiang, H., 2014. Regional sea level variation on interannual timescale in the East China Sea. Int. J. Geosci. 5, 1405-1414. http://dx.doi.org/10. 4236/ijg.2014.512114.
Zhuang, W., Oiu, B., Du, Y., 2013. Low-frequency western Pacific Ocean sea level and circulation changes due to the connectivity of the Philippine Archipelago. J. Geophys. Res. Oceans 118 (12), 6759-6773.

Zuo, J., He, Q., Chen, C., Chen, M., Xu, Q., 2012. Sea level variability in the East China Sea and its response to ENSO. Water Sci. Eng. 5 (2), 1-6. 